\title{
HUBUNGAN KETERLIBATAN DAN KONSISTENSI DENGAN PRODUKTIVITAS KERJA PERAWAT DI RSUD I LAGALIGO WOTU
}

\author{
Anas Budi ${ }^{1)}$, Armawati Abidin 2) \\ 1,2 Jurusan Keperawatan, STIKes Bataraguru \\ Email: anasbudi46@yahoo.com
}

\section{Diterima: Desember 2020, Diterbitkan: Desember 2020}

\begin{abstract}
ABSTRAK
Budaya organisasi memiliki pengaruh yang kuat di seluruh rumah sakit, selain menjadi identitas, juga merupakan acuan atau pedoman bagi perilaku perawat. Hubungan budaya organisasi dengan produktivitas kerja perawat membawa dampak yang positif pada rumah sakit, dimana budaya organisasi dapat menuntun perawat menjadi produktif. Penelitian ini bertujuan mengetahui sejauh mana keterlibatan dan konsistensi dengan produktivitas kerja perawat di RSUD I Lagaligo Wotu Kabupaten Luwu Timur. Penelitian ini merupakan penelitian kuantitatif dengan desain penelitian diskriptif korelasi. Subyek penelitian adalah 81 perawat pelaksana di ruang rawat inap RSUD I Lagaligo Luwu Timur, alat ukur yang digunakan adalah kuesioner. Hasil analisis bivariat menggunakan uji spearman correlation menunjukkan bahwa ada hubungan positif dan signifikan antara keterlibatan dan produktifitas kerja dengan nilai $\mathrm{p}=0,001$, serta ada hubungan positif dan signifikan antara konsistensi dan produktifitas kerja dengan nilai $\mathrm{p}=0,001$.
\end{abstract}

Kata Kunci: Keterlibatan, Konsistensi, Produktivitas Kerja, Perawat

\section{ABSTRACT}

The organizational culture has a strong influence throughout the hospital, apart from being an identity, it is also a reference or guide for nurses' behavior. The relationship between organizational culture and work productivity of nurses has a positive impact on the hospital, where organizational culture can lead nurses to be productive. This study aimed to find out the extent of involvement and consistency with the work productivity of nurses in Lagaligo Wotu Regional Hospital, East Luwu Regency. This study was a quantitative research with a correlation descriptive research design. The research subjects were 81 nurses in the inpatient room of I Lagaligo East Luwu Regional Hospital. The measuring instrument used was a questionnaire. The results of bivariate analysis using the Spearman Correlation test showed that there was a positive and significant relationship between work involvement and productivity with a value of $p=0.001$, and there was a positive and significant relationship between consistency and work productivity. with $p$ value $=0.001$.

Keywords: Involvement, Consistency, Work Productivity, Nurse. 


\section{PENDAHULUAN}

karakter organisasi merupakan mengarahkan hubungan kerja sehari-hari karyawan dan menuntun mereka tentang berperilaku dan berkomunikasi dalam organisasi, serta membimbing hirarki perusahaan dibangun dan merangsang tingkah laku staf menjadi produktif (Tseng, 2010).

Denison \& Mishra (1993) menyatakan bahwa budaya organisasi terdiri dari empat dimensi yaitu keterlibatan, konsistensi, adaptasi, dan misi. Penelitian dari Afiah, Maidin dan Bahar (2013) tentang budaya dan efektivitas rumah sakit di RSU Labuang Baji Makasar, untuk budaya organisasi di RSU Labuang Makasar didapatkan tingkat keterlibatan sedang $56.7 \%$, tingkat konsistensi tinggi sebesar $53.3 \%$, dimensi adaptasi dinilai cukup $76.7 \%$, dimensi misi tinggi sebesar $83.3 \%$. Hasil penelitian tersebut menunjukkan bahwa budaya organisasi yang kuat tidak menunjukkan pengaruh dalam meningkatkan efektivitas organisasi.

Robbins (1996) menyatakan bahwa organisasi dengan budaya yang lemah, individu di dalamnya tidak memiliki kesiapan akan terjadinya sebuah perubahan. Penelitian tersebut membantu untuk meningkatkan pemahaman eksekutif keperawatan untuk dapat mengembangkan budaya organisasi rumah sakit dalam mempromosikan komitmen organisasi. Pemahaman tentang budaya organisasi menyebabkan komitmen perawat yang tinggi, dengan kata lain budaya organisasi sangat efektif dalam mengembangkan kerja yang positif bagi perawat (Hsi Chi et al., 2012)

Keperawatan sebagai salah satu pemberi pelayanan di rumah sakit wajib memberikan layanan perawatan yang prima, efisien, dan produktif kepada masyarakat. Sebagai salah satu tenaga kesehatan yang terbesar di rumah sakit yang jumlahnya mencapai $40 \%$ $60 \%$ (Huber, 2014). Oleh karena itu produktivitas perawat menjadi sangat penting untuk diperhatikan, khususnya dalam memberikan pelayanan keperawatan di rumah sakit.

Hersey \& Goldsmith (1980) menjelaskan ada tujuh faktor dalam produktivitas kerja sumber daya manusia: 1) kemampuan (ability), 2) kejelasan (clarity), 3) bantuan (help), 4) insentif (incentive), 5) evaluasi (evaluation), 6) validitas (validity), dan 7) lingkungan (environment).

Penelitian Rosa et al (2013), menemukan produktivitas kerja perawat pelaksana di ruang rawat inap RSUPN. Dr. Ciptomangunkusumo kategori kurang baik. Sejalan dengan penelitian Minarsih (2011), produktivitas kerja perawat di instalasi rawat inap non bedah (penyakit dalam) RSUP. Dr Jamil Padang tergolong rendah $(54.7 \%)$.

Masalah diatas dalam penelitian mengacu dari hasil-hasil penelitian terdahulu. Maka rumusan masalah dan tujuan penelitian ini adalah sejauh mana hubungan budaya organisasi terkait keterlibatan dan konsistensi dengan produktivitas kerja perawat di Rumah Sakit Umum Daerah I Lagaligo Wotu Kabupaten Luwu Timur.

\section{METODE PENELITIAN}

Metode penelitian ini menggunakan penelitian kuantitatif dengan desain penelitian diskriptif korelasi, Penelitian ini dilakukan di IGD RSUD I Lagaligo Wotu tahun 2020 dengan Teknik pengambilan sampel yang digunakan dalam penelitian ini adalah menggunakan metode probability random sampling dengan tehnik simple random sampling yaitu 81 perawat. Instrumen dalam penelitian dengan menggunakan kuesioner. Adapun pernyataan dalam penelitian ini adalah pernyataan tentang keterlibatan perawat, konsistensi perawat dan produktifitas kerja perawat. univariat dan bivariat. analisis bivariat untuk mengetahui Hubungan antara variabel dependen dengan independen menggunakan uji Correlasi. 
HASIL DAN PEMBAHASAN

Berdasarkan hasil penelitian dapat diketahui distribusi responden berdasarkan Keterlibatan dapat dilihat pada tabel 1 sebagai berikut:

Tabel 1. Distribusi responden berdasarkan keterlibatan perawat di RSUD I Lagaligo Wotu Kabupaten Luwu Timur.

\begin{tabular}{ccc}
\hline Keterlibatan & Jumlah (n) & Persentase (\%) \\
\hline Tinggi & 76 & $93.8 \%$ \\
Rendah & 5 & $6.2 \%$ \\
\hline Jumlah & 81 & $100 \%$ \\
\hline
\end{tabular}

(Sumber : data primer 2020)

Dari hasil tabel diatas menunjukkan bahwa keterlibatan perawat memiliki mayoritas keterlibatan yang tinggi sebesar $93,8 \% \quad(n=76)$ responden dan rendah sebanyak $6,2 \%(\mathrm{n}=5)$ penilaian penelitian mengunakan cara ukur STS $=1 \mathrm{TS}=2 \mathrm{~S}=3$ $\mathrm{SS}=4$ dan skala ukur yang digunakan dalam kuesioner adalah skala ordinal.

Berdasarkan hasil penelitian dapat diketahui distribusi responden berdasarkan konsistensi dapat dilihat pada tabel 2 sebagai berikut:

Tabel 2. Distribusi responden berdasarkan konsistensi perawat di RSUD I Lagaligo Wotu Kabupaten Luwu Timur.

\begin{tabular}{ccc}
\hline Konsistensi & Jumlah (n) & Persentase (\%) \\
\hline Tinggi & 73 & $90,1 \%$ \\
Rendah & 8 & $9,9 \%$ \\
\hline Jumlah & 81 & $100 \%$ \\
\hline
\end{tabular}

(Sumber : data primer 2020)

Dari hasil tabel diatas menunjukkan bahwa konsistensi perawat pelaksana mayoritas konsistensi tinggi berjumlah $90,1 \% \quad(\mathrm{n}=73)$ responden dan rendah berjumlah $9,9 \%(n=8)$ penilaian penelitian mengunakan cara ukur STS $=1 \mathrm{TS}=2 \mathrm{~S}=3$ $\mathrm{SS}=4$ dan skala ukur yang digunakan dalam kuesioner adalah skala ordinal.
Berdasarkan hasil penelitian dapat diketahui distribudi responden berdasarkan Produktifitas kerja perawat, dapat dilihat pada tabel 3 sebagai berikut:

Tabel 3. Distribusi responden berdasarkan produktifitas kerja perawat di RSUD I Lagaligo Wotu Kabupaten Luwu Timur Produktifitas Jumlah(n)

Presentase $(\%)$

\begin{tabular}{lcc}
\hline Baik & 74 & $91,4 \%$ \\
Buruk & 7 & $8,6 \%$ \\
\hline Jumlah & 81 & $100 \%$ \\
\hline \multicolumn{2}{l}{ (Sumber : data primer } & $2020)$
\end{tabular}

Dari hasil tabel diatas menunjukkan bahwa produktifitas kerja perawat pelaksana mayoritas produktifitas kerja tinggi berjumlah 91,4\% $(\mathrm{n}=74)$ responden dan rendah berjumlah $8,6 \%(\mathrm{n}=7)$ penilaian penelitian mengunakan cara ukur STS $=1$ $\mathrm{TS}=2 \quad \mathrm{~S}=3 \quad \mathrm{SS}=4$ dan skala ukur yang digunakan dalam kuesioner adalah skala ordinal.

Hubungan antara keterlibatan dengan produktifitas kerja perawat pelaksana di RSUD I Lagaligo Wotu Kabupaten Luwu Timur, dapat dilihat pada tabel 4 sebagai berikut:

Tabel 4. Hubungan keterlibatan dengan produktifitas kerja perawat pelaksana di

RSUD I Lagaligo Wotu Tahun 2020

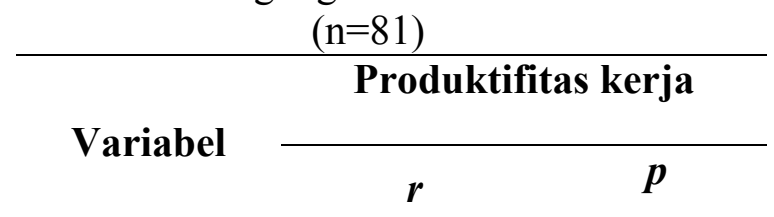

\begin{tabular}{lll}
\hline Keterlibatan & 0.469 & $0.001 *+$
\end{tabular}

Ket:+ Hasil dari uji spearman correlation,

* Signifikan pada alpha $=0,05$

Tabel diatas menunjukkan bahwa ada hubungan yang bermakna dan signifikan antara ketelibatan dengan produktifitas kerja yaitu $(p=0.001)$ dengan kekuatan sedang dan arah hubungan positif $(r=469)$ yang berada kisaran $0,4-<0,6$. Hal ini 
berarti semakin tinggi keterlibatan maka semakin tinggi pula produktifitas kerja di Rumah Sakit I Lagaligo Wotu Kabupaten Luwu Timur.

Menurut Indayati et al., (2012) menyatakan bahwa Keterlibatan atau partisipasi pegawai dalam aktivitas-aktivitas kerja penting untuk diperhatikan karena dengan adanya keterlibatan pegawai akan menyebabkan mereka akan mau dan senang bekerja sama, baik dengan pimpinan ataupun dengan sesama teman kerja. Robbins \& Coulter (2010), menyatakan budaya organisasi yang kuat akan menumbuhkembangkan rasa tanggung jawab yang besar dalam diri karyawan sehingga mampu memotivasi untuk menampilkan kinerja yang paling memuaskan, mencapai tujuan yang lebih baik, dan pada gilirannya akan memotivasi seluruh anggotanya untuk meningkatkan produktivitas kerja.

Indayati et al., (2012) menyatakan bahwa Salah satu cara yang dapat dipakai untuk memancing keterlibatan pegawai adalah dengan memancing partisipasi atau keterlibatan mereka dalam berbagai kesempatan pembuatan keputusan. Keterlibatan karyawan bisa memberi motivasi instrinsik kepada para karyawan dengan cara meningkatkan peluang pertumbuhan, tanggung jawab, dan keterlibatan dalam pekerjaan itu sendiri. salah satu yang akan menjadi sumber utama keunggulan kompetitif bagi organisasi yang mengembangkan basis karyawan berkomitmen, bukan karena mereka dibayar untuk berkomitmen, tetapi karena mereka memilih untuk berkomitmen. Hal senada dinyatakan dalam penelitian (Hsu, 2009) menyatakan budaya organisasi dapat meningkatkan komitmen organisasi dan bahkan kinerja pelayanan rumah sakit. Lebih lanjut (Hsi Chi et al., 2012) menyatakan pemahaman tentang budaya organisasi menyebabkan komitmen perawat yang tinggi, dengan kata lain budaya organisasi sangat efektif dalam mengembangkan kerja yang positif bagi perawat.
Hasil wawancara dengan lima orang perawat pelaksana, mengatakan bahwa pemimpin tidak melibatkan mereka dalam pembuatan peraturan, tata tertib atau pembuatan kebijakan yang berkaitan dengan kegiatan keperawatan. Hasil wawancara dengan seorang staf manejer keperawatan menyatakan, perawat dalam melakukan asuhan keperawatan harus dapat memperlakukan pasien sebagai keluarganya sendiri, mereka harus bisa memberikan yang terbaik bagi pasien. Oleh karena itu mereka harus dapat mengembangkan diri, dan rumah sakit memberikan kesempatan untuk pelatihan, seminar, workshop baik didalam atau diluar rumah sakit, agar mereka lebih terampil lagi. Pernyataan tersebut didukung oleh 5 reponden $(100 \%)$ bahwa mereka mengikuti seminar, workshop, pelatihan secara bergiliran baik didalam atau diluar rumah sakit.

Apabila perawat pelaksana di RSUD I Lagaligo Wotu Luwu Timur dilibatkan dan memberikan kontribusi kepada rumah sakit dalam penetapan peraturan, tata tertib, atau kebijakan, maka akan menimbulkan kebanggan dalam diri, yang akhirnya akan berusaha meningkatkan kinerja sehingga produktivitasnya akan meningkat juga. Keterlibatan yang perawat pelaksana dalam organisasi, meningkatkan rasa kepemilikan, tanggung jawab, untuk mencapai tujuan organisasi. Meningkatkan pemberdayaan perawat pelaksana dan pengembangan kemampuan di RSUD I Lagaligo Wotu Luwu Timur akan mempengaruhi kinerja organisasi secara keseluruhan termasuk juga kinerja para manajer. Budaya organisasi yang menerapkan budaya keterlibatan memampukan pihak manajer dapat melaksanakan tugasnya lebih optimal. Budaya organisasi (keterlibatan) dapat membantu rumah sakit mengantisipasi dan beradaptasi dengan perubahan lingkungan, memungkinkanya mengidentifikasi dan mengeksploitasi peluangpeluang baru untuk mencapai tujuan. Para anggota organisasi dalam hal ini perawat pelaksana 
percaya bahwa mereka dapat menata secara efektif masalah baru dan peluang yang mereka temui serta siap menanggung resiko. Hal ini dapat terlaksana dengan baik karena ada kesepakatan antara pemimpin dan perawat yang terampil menggabungkan beragam titik pandang, dan kegiatan organisasi yang terkoordinasi dan terintegrasi.

Hubungan antara Konsistensi dengan Produktifitas kerja perawat di RSUD I Lagaligo Wotu Kabupaten Luwu Timur dapat dilihat pada tabel 5 sebagai berikut:

Tabel 5. Hubungan konsistensi dengan produktifitas kerja perawat pelaksana di RSUD I Lagaligo Wotu Kabupaten Luwu Timur Tahun $2020(n=81)$

\section{Produktifitas kerja}

\begin{tabular}{ccc} 
VARIABEL & \multicolumn{2}{c}{$\boldsymbol{p}$} \\
\cline { 2 - 3 } & $\boldsymbol{r}$ & $0.001^{*}+$
\end{tabular}

Ket : + Hasil dari uji spearman correlation, * Signifikan pada alpha $=0,05$

Tabel diatas menunjukkan bahwa ada hubungan yang bermakna dan signifikan antara Dimensi Budaya organisasi (konsistensi) dengan produktifitas kerja yaitu ( $p=0.001$ ) dengan kekuatan interpretasi kuat dan arah hubungan positif $(r=782)$ yang berada kisaran $0,6-<0,8$. Hal ini berarti semakin tinggi konsistensi maka semakin tinggi pula produktifitas kerja di Rumah Sakait I Lagaligo Wotu Kabupaten Luwu Timur.

Penelitian tersebut sejalan dengan (Efliani, 2014) tentang Pengaruh budaya organisasi terhadap kinerja perawat di Rumah Sakit Umum Daerah Dr. Moewardi Surakarta sebagian besar berpengaruh dibuktikan dengan nilai t hitung lebih besar dari $\mathrm{t}$ tabel $(2,076>1,985)$; Pengaruh komitmen organisasional terhadap kinerja perawat di Rumah Sakit Umum Daerah Dr. Moewardi Surakarta sebagian besar berpengaruh dibuktikan dengan nilai t hitung lebih besar dari t tabel $(3,294>1,985)$. Sebagaimana Denison \& Mishra (1993) menyatakan konsistensi adalah nilai dan sistim yang mendasari kekuatan suatu budaya.

Hasil wawancara dengan seorang perawat senior menyatakan bahwa pemimpin hanya memilih beberapa orang yang dipercayai (yang disukai) saja dan, kurang perhatian pada stafnya, serta tidak ada penghargaan yang diberikan kepada perawat. Kurang koordinasi antara ruangan, masing-masing ruangan membuat kebijakannya. Kaitannya dengan budaya organisasi terkait konsistensi adalah apabila pimpinan secara aktif perduli pada stafnya dengan cara memberikan perhatian, memberikan staf penghargaan bagi yang berprestasi, menjunjung tinggi peraturan dan tegas dalam pengambilan keputusan dan menjadi role model kepada bawahannya, maka hal akan memberikan rasa aman dan nyaman bagi perawat pelaksana, sehingga menimbulkan gairah pada perawat untuk bekerja secara produktif.

Pengaruh pemimpin dalam budaya organisasi (konsistensi) di organisasi sangat besar dampaknya terhadap kinerja bawahan sebagaimana penelitian KaneUrrabazo (2006) menunjukkan bahwa kualitas yang lebih tinggi pada eksekutif keperawatan memiliki pengaruh positif terhadap budaya organisasi di rumah sakit. Penelitian lain dari (Hsu, 2009), menyatakan budaya organisasi dapat meningkatkan komitmen organisasi dan bahkan kinerja pelayanan rumah sakit. Sejalan dengan (Robbins \& Coulter, 2010) menyatakan bahwa para manejer bertanggung jawab secara langsung atas keberhasilan atau kegagalan organisasi yang mereka pimpin. Manejer bertugas membuat keputusan, dan mereka ingin keputusan tersebut menjadi keputusan yang baik.

Organisasi rumah sakit juga memiliki budaya yang dapat menjadi perekat untuk berinteraksi secara bersama-sama dan 
saling memberikan makna pada tujuan kolektif (Santoso, 2018). budaya maupun sistem penghargaan berpengaruh secara simultan dan parsial terhadap efektivitas organisasi. Budaya organisasi pengaruh lebih kuat terhadap efektivitas organisasi dibandingkan dengan pengaruh yang diberikan oleh sistem penghargaan (Cesilya, 2015)

Budaya organisasi yang kuat, memiliki dampak yang besar terhadap perilaku perawat, terutama dalam memberikan pelayanan asuhan keperawatan kepada pasien yang akhirnya pada peningkatan produktivitas kerja perawat. Budaya organisasi yang tinggi, nilai-nilai inti organisasi dipegang teguh oleh setiap anggota organisasi. Timbulnya kesepahaman pimpinan untuk menjadikan visi dan misi sebagai pedoman akan memudahkan untuk mencapai tujuan yang telah ditetapkan.

\section{KESIMPULAN}

Keterlibatan perawat mempunyai hubungan erat dengan produktifitas kerja perawat di RSUD I Lagaligo Wotu Kabupaten Luwu Timur mempunyai nilai $p$ value $0,001<$ alpha 0,05 .

Konsistensi perawat mempunyai hubungan erat dengan produktifitas kerja perawat di RSUD I Lagaligo Wotu Kabupaten Luwu Timur dengan nilai $p$-value $0,001<$ alpha 0,05 .

\section{UCAPAN TERIMAKASIH}

Alhamdulilah Puji syukur tak terhingga terhadap Yang Maha Kuasa, Tak lupa saya ucapkan banyak terimah kasih kepada para pimpinan perguruan tinggi yang banyak membantu penelitian kami hingga selesai.

Dan tak lupa saya ucapkan terima kasih kepada direktur Rumah Sakit dan stafnya yang bisa diajak kerjasama dalam penelitian ini sehingga selesai tanpa kendala.

\section{DAFTAR PUSTAKA}

Afiah, R. N., Maidin, A., \& Bahar, B. (2013). Budaya Dan Efektifitas Organisasi Rumah Sakit (Di RSUD Haji Makassar dan RSU Labuang Baji Makassar. E-journal Program Pascasarjana Universitas Hasanuddin

Cesilya, R. (2015). Budaya organisasi, sistem penghargaan dan efektivitas organisasi. Jurnal Ilmu Administrasi Negara, 13(3), 300-306.

file://C:/Users/DELL/Downloads/D ocuments/EFEKTIVITAS/Jurnal/BU DAYA ORGANISASI, SISTEM PENGHARGAAN DAN EFEKTIVITAS ORGANISASI.pdf

Denison, D. R., \& Mishra, A. K. (1993). Toward a Theory of Organization and Effectiveness. Organization Science, 6(2), 204-223.

Efliani, D. (2014). Pengaruh Motivasi, Budaya Organisasi Dan Komitmen Organisasional Terhadap Kinerja Perawat Di Rsud Dr. Moewardi Surakarta [Universitas Muhammadiyah Surakarta]. In Applied Microbiology and Biotechnology (Vol. 85, Issue 1). https://doi.org/10.1016/j.bbapap.201 3.06.007

Hersey, \& Goldsmith. (1980). The ACHIEVE system: a humanperformance problem-solving model. Trends and Issues in OD: Current Theory and Practice. josseyBass.

Hsi Chi, Hsiao, J. C., Chang, Ya Ling, \& Tu. (2012). The influence of hospital organizational culture on organizational commitment among nursing executives. African Journal of Business Management, 6(44), 10888-10895.

https://doi.org/10.5897/ajbm11.1510

Hsu, H.-Y. (2009). Organizational Learning Culture's Influence on Job Satisfaction, Organizational Commitment, and Turnover Intention among $R \& D$ Professionals in 
Taiwan during an Economic

Downturn. In Partial Fufillment of

The Requirements For The Degree Of Doctor Of Philosophy.

Huber. (2014). Leaderhip \& Nursing Care Management, Fifth Editio (5th ed.). University Of Lowa City.

Indayati, N., Thoyib, A., \& Rofiaty. (2012).

Pengaruh Keterlibatan Karyawan, Budaya Organisasi, dan Gaya

Kepemimpinan terhadap Komitmen

Organisasional dalam Meningkatkan

Kinerja Karyawan ( Studi pada

Universitas Brawijaya ). Jurnal

Aplikasi Manajemen, 10(2), 344-356.

https://jurnaljam.ub.ac.id/index.php/ja $\mathrm{m} /$ article/view/425/465

Kane-Urrabazo, C. (2006). Management's role in shaping organizational culture. Journal of Nursing Management, 14(3), 188-194.

https://doi.org/10.1111/j.1365-

2934.2006.00590.x

Minarsih, M. (2011). Hubungan beban

kerja dengan produktivitas kerja perawat di IRNA non Bedah (penyakit dalam) RSUP. DR Jamil Padang. UNAND Padang.

Robbins. (1996). Perilaku organisasi:

Konsep, kontroversi, aplikasi. Penerbit PT Prenhallindo.

https://scholar.google.com/scholar?hl= id\&as_sdt $=0 \% 2 \mathrm{C} 5 \& \mathrm{q}=$ Robbins $\% 2 \mathrm{C}+$ S. + P. $+\% 281996 \% 29 .+$ Perilaku + organ isasi $\% 2 \mathrm{C}+$ konsep $\% 2 \mathrm{C}+$ kontroversi $+\mathrm{d}$ an+aplikasi.+edisi+keenam.+Jakarta\% 3A+PT.+Bhuana+ilmu+populer\&btnG $=$

Robbins, S., \& Coulter, M. (2010). Manajemen, Edisi 10, Jilid 1 (10th ed.). Erlangga.

Rosa, E. M., Nurachmah, E., \&

Budihartono. (2013). Hubungan

Antara Kohesivitas Kelompok Dan

Sikap Perawat Pelaksana Dengan

Produktivitas Kerja Perawat Pelaksana

Diruang Rawat Inap Rsupn. Dr.

Ciptomangunkusumo. Jurnal

Medicoeticolegal, 15(3-2).

Santoso, Y. H. (2018). Dinamika Budaya
Organisasi Rumah Sakit sebagai Kompas Moral Antikorupsi.

Universitas Airlangga.

Tseng, S. M. (2010). The correlation between organizational culture and knowledge conversion on corporate performance. Journal of Knowledge Management, 14(2), 269-284. https://doi.org/10.1108/13673271011 032409 